\title{
MARGINALIDAD, PARTICIPACIÓN Y ESTRUCTURA AGRARIA EN AMÉRICA LATINA *
}

\author{
Rodolfo STAVENHAGEN \\ Instituto Internacional de Estudios Laborales, Ginebra
}

\section{Desarrollo y PaRTicipactón SOctal}

EN AÑOS RECIENTES se ha venido a considerar el proceso de desarrollo no sólo en términos económicos, sino también en términos sociales y políticos. Ya no se trata solamente de reconocer la existencia de "aspectos" sociales del desarrollo. Se reconoce más bien que este proceso es el resultado de un conjunto de factores económicos, sociales y políticos. En el estudio del proceso de desarrollo se hace cada vez más énfasis en la estructura de las instituciones y la naturaleza de las relaciones entre grupos sociales. El desarrollo económico es considerado ahora únicamente como un aspecto entre otros del cambio social concebido en términos más amplios. Este cambio en función del desarrollo es calificado a veces como el proceso de modernización. Pero a menos de que simplemente utilicemos estos dos conceptos como sinónimos, debe reconocerse desde el principio que ciertos aspectos de la modernización pueden ocurrir aun sin que exista el desarrollo. De hecho, ciertas estructuras "atrasadas" o "subdesarrolladas" pueden ser modernizadas parcialmente por las étites o clases gobernantes tradicionales, como un intento deliberado de impedir cambios más profundos o radicales.

Un aspecto importante de la modernización es el papel que desempeñan los diversos grupos y clases de la sociedad que intervienen directamente en este proceso. El desarrollo (o el cambio social, o la modernización, según el término que deseemos utilizar), ¿es el producto de las "fuerzas impersonales de la historia", o la elección consciente de una élite activa y dedicada, o el resultado de la emergencia de las masas como poderosos grupos de presión en las sociedades contemporáneas? En el plano político, la modernización es considerada a veces como un proceso de creciente complejidad en la distribución y funcionamiento de roles. A un nivel más psicológico, se hace referencia a ciertos tipos de cambios en las actitudes, los valores y las normas de comportamiento. También un aspecto esencial parece ser la creciente participación de diferentes estratos de la población en la toma de decisiones económicas y políticas, así como en la implementación de políticas de desarrollo y, naturalmente, en los resultados o

* El presente artículo constituye una síntesis parcial de los temas tratados en el Simposio sobre la Participación Social en América Latina, que tuvo lugar en El Colegio de México, del 14 al 16 de octubre de 1969, bajo los auspicios del Instituto Internacional de Estudios Laborales, de la OIT. 
frutos de dichas políticas. A este proceso se da el nombre de participación social, y algunos estudiosos lo consideran como un elemento clave en el proceso de desarrollo. Se arguye, de hecho que no puede haber un "verdadero" desarrollo sin la participación de todos los diversos sectores de la sociedad. En cambio, entre los obstáculos al desarrollo mencionados con mayor frecuencia está el hecho que en las sociedades tradicionales que son tan características de los países menos desarrollados, el poder se encuentra en manos de pequeños grupos privilegiados, las estructuras estratificadas son fuertes y la mayoría de la población está efectivamente impedida de cualquier tipo de participación significativa en la toma de decisiones políticas o económicas.

Se solía pensar que el desarrollo político y social acompañaría al desarrollo económico; que la mayor producción y las altas tasas de crecimiento en las economías atrasadas conducirían casi automáticamente a la modernización política y a crecientes niveles de participación entre la población. En América Latina pueden encontrarse los comienzos de un crecimiento autosostenido en los años treinta y particularmente en el período de la posguerra. Aunque están lejos de ser satisfactorias las tasas de crecimiento per capita, y a pesar de que en algunos países se ha producido incluso un decrecimiento del producto en años recientes, el desarrollo económico es la principal meta declarada de los gobiernos nacionales de la región.

Pero las correlaciones sociales y políticas del crecimiento económico nos proporcionan un cuadro complejo y de ninguna manera armónico. Durante los años treinta y cuarenta surgieron nuevos grupos sociales que insisten en ser escuchados, principalmente la clase obrera industrial y los sectores medios urbanos vinculados a las burocracias del Estado y al proceso de crecimiento urbano e industrial. Los gobiemos deben enfrentarse a una variedad creciente de intereses en competencia o en conflicto. Sin embargo, la tendencia general parece ser más bien de menor, y no de mayor, democracia política. La articulación de estos diferentes intereses se expresa igualmente (o tal vez más) a través de modelos "burocrático-corporativos" que en el libre juego de partidos políticos que corresponden al tipo occidental clásico. El desarrollo económico parece haber aumentado y no disminuido la desigualdad entre regiones y clases sociales.

La historia de las naciones latinoamericanas, primero como sociedades coloniales durante trescientos años, luego como países económicamente dependientes y estrechamente vinculados al desarrollo de un pequeño número de centros metropolitanos mundiales, ha determinado en gran medida la naturaleza de sus estructuras económicas y políticas internas. En el estado "oligárquico" tradicional de América Latina la participación social y política activa estaba limitada a las élites propietarias. En las economías "agroexportadoras" basadas en el sistema de la hacienda o la plantación y la exportación de productos agrícolas, no había lugar para la integración de los peones indígenas o los campesinos sin tierra en el proceso de toma de decisiones de la sociedad.

Pero los primeros signos de la industrialización, el crecimiento de las ciudades, el desarrollo de clases sociales urbanas y la expansión de los mercados internos, entre otros factores, han afectado seria- 
mente la estabilidad del viejo sistema. En algunos paises el viejo orden fue destruido por revoluciones violentas y reemplazado por nuevos arreglos (México, Bolivia y Cuba siguieron cada uno su camino propio después de haber roto el orden establecido). En otros países, circunstancias históricas particulares han permitido el rápido desarrollo de unos cuantos centros dinámicos de crecimiento pero casi no han tocado las estructuras rurales tradicionales (éste es el caso particularmente del Brasil). En otros más no parecen haber ocurrido transformaciones profundas en las estructuras tradicionales, pero éstas, sin embargo, han sabido adaptarse al lento "flujo" del cambio secular a través de la modernización de algunos de sus aspectos más anacrónicos.

En este proceso de cambio por el que están atravesando actualmente los países latinoamericanos, el problema de la participación social reviste una importancia fundamental. No sólo debemos preguntarnos quién introduce y promueve los cambios sino también, y principalmente, cuáles son los grupos sociales involucrados y quiénes se benefician de los cambios. ¿Cómo se organizan los diferentes grupos sociales para defender sus intereses y plantear sus demandas al sistema social y político? ¿Cuáles son las condiciones que fomentan la participación de algunos grupos y la no participación de otros? ¿Cuáles son los diferentes niveles y grados de intensidad de participación y qué amplitud tienen las demandas expresadas? Y, particularmente, ¿cuáles son los grupos estratégicos en el proceso de desarrollo y cuál es su potencial de participación?

Existen, desde luego, diferentes tipos de participación, y si se utiliza el concepto en su sentido más amplio, entonces toda vida social implica alguna forma de participación. La gente participa en las actividades organizadas de su comunidad, ya sea sobre una base rutinaria y cotidiana, o periódicamente en función de objetivos específicos. Los individuos forman parte de instituciones tradicionales que sirven para mantener funcionando a la sociedad. También integran toda clase de grupos más allá de su círculo familiar inmediato.

No nos preocupa aquí esta forma "tradicional" de participación, sino más bien los diferentes tipos de actividad organizada, en sociedades altamente diferenciadas, mediante la cual un grupo social de status bajo logra expresar sus necesidades o demandas, defender sus intereses comunes, alcanzar determinados objetivos económicos, sociales o políticos, o influir de manera directa o indirecta en los poderes públicos. Dicha actividad puede o no estar vinculada directa o indirec. tamente con los esfuerzos de desarrollo realizados por las autoridades gubernamentales; puede o no tener explícitamente una meta de desarrollo. La clave de la participación, en nuestra opinión, no está tanto en su vinculación con el "desarrollo" ( según los diversos significados de este concepto), cuanto en el hecho de que puede llegar a ser un instrumento para la expresión organizada de necesidades socialmente determinadas, por parte de un grupo de status bajo (explotado, oprimido, dependiente o marginalizado). Esta expresión organizada de necesidades ya constituye, por sí misma, uno de los factores potenciales principales del desarrollo social y político. Por consiguiente, la participación no deberá entenderse solamente como participación en 
un sistema dado, sino puede referirse también a acciones organizadas (por ejemplo, revolucionarias) que rechazan la estructura social establecida e intentan cambiarla.

Se advertirá que esta concepción de la participación social es más amplia que la definición utilizada por la Oficina Internacional del Trabajo en su proyecto de investigación sobre la participación en el desarrollo en América Latina. De acuerdo con dicha definición, participación significa "la contribución de individuos o de grupos de la población activa a la aceleración del desarrollo económico y social". Aquí el énfasis se coloca en:

a) la participación en el desarrollo, o sea, aquella que puede, directa o indirectamente, vincularse con una política que movilice a los individuos con el objeto de crear empleos y riqueza, tendiendo al mejoramiento de las condiciones de vida; $y$

b) la participación en el trabajo y en torno a éste, que se desenvuelve a dos niveles: i) la participación "primaria", es decir, la participación de los individuos en los grupos profesionales, económicos y sociales; y ii) la participación "secundaria", que puede definirse como el esfuerzo voluntario ejercido por las agrupaciones profesionales y sociales que disfrutan de cierta autonomía, para contribuir a la acción en favor del desarrollo ejecutada por las autoridades gubernamentales. ${ }^{1}$

Es obvio que no todas las actividades organizadas ni todos los grupos sociales tienen la misma importancia o el mismo impacto en el desarrollo social y político. Dentro del marco de la situación latinoamericana, hay que enfatizar particularmente aquellas actividades que resultan directamente de desequilibrios internos y tensiones en la estructura social y económica; aquellas que conducen, o cuyo objetivo es conducir, a la transformación total o parcial de la estructura; aquellas que contribuyen al ajuste de ciertos sectores de la población a estructuras cambiantes; $y$, finalmente, aquellas que tienden a aumentar el poder de negociación político y económico y el status social de los grupos involucrados.

Desde luego, existen muchos tipos de participación social que parecen tener estos objetivos pero que en realidad llegan a ser contraproducentes, es decir, que son "funcionales" a los sistemas actuales del poder en América Latina y que son utilizados hábilmente por los grupos dirigentes para mejorar su propia situación. Uno de los principales problemas en el campo de la participación social es el de determinar en qué circunstancias ocurren estos fenómenos.

Es evidente que esta manera de entender la participación social reviste una importancia particular cuando el proceso ocurre entre aquellos sectores de la población que no han participado previamente, debico a su posición en el sistema socioeconómico. Por lo tanto, es necesario comprender las condiciones que determinan la participación o no participación de grupos e individuos en la sociedad, y esto a su

1 OIT, "La participación en el desarrollo en América Latina", documento presentado al Simposio sobre la Participación Social en América Latina, IIEL, México, 14-16 de octubre de 1969 (mimeografiado). 
vez requiere comprender las relaciones entre la población participante y no-participante, entre las élites y laś masas y entre diferentes clases sociales. En otras palabras, las diversas características de la participación social están íntimamente ligadas a la estructura socioeconómica y al funcionamiento del sistema político.

\section{El MARCO SOCIAL Y ECONÓMTCO DE LA PARTICIPACIÓN SOCIAL eN AMÉrica LatiNa}

Una estructura agraria basada en latifundios y la explotación de la fuerza de trabajo esclava o servil caracterizó durante varios siglos a la sociedad latinoamericana. Desde luego, existían variantes locales y regionales, pero en esencia esta estructura constituía la base del poder político de élites gobernantes relativamente pequeñas y concentradas (las llamadas "oligarquías"), del cual estaba virtualmente excluida la mayoría de la población. La participación social, tal como se ha definido aquí, no abarcaba a las clases explotadas de la sociedad. Éstas, que constituían la mayoría de la población, se encontraban efectivamente subordinadas al sistema, el cual logró mantenerse a través de los siglos mediante el uso combinado de la tradición y la fuerza. Las principales instituciones de la sociedad - la estructura agraria, el sistema educative, el sistema jurídico, la burocracia hispano-colonial cuyas principales características se mantuvieron incluso en el período independiente, la Iglesia, el ejército y la ideología dominante- constituían una combinación eficiente para mantener el orden y la estabilidad en las sociedades colonial y postcolonial. Al mismo tiempo no faltaron movimientos sociales dirigidos contra este estado de cosas. La historia de las sociedades latinoamericanas proporciona muchos ejemplos de revueltas de esclavos, rebeliones indígenas, levantamientos campesinos e insurrecciones urbanas, la mayoría de los cuales fueron reprimidos con éxito por los grupos dirigentes.

Las guerras de independencia a principios del siglo xIX, si bien lograron movilizar grandes sectores de la población, no cambiaron básicamente la estructura social. ${ }^{2}$ Los principales aspectos de una sociedad dependiente y colonial subsistieron aun después de haberse logrado la independencia política. Desde el punto de vista económico, los intereses británicos desplazaron a los de las antiguas metrópolis coloniales.

Las instituciones políticas democráticas se inspiraron, cuando menos en el papel, en las de Francia y Estados Unidos, pero por muchos motivos complejos, nunca llegaron a funcionar bien ni a integrarse en las sociedades a las que habian sido injertadas por los estadistas liberales e idealistas quienes las introdujeron. La distancia entre la norma y la realidad política ha sido desde entonces una de las características críticas más persistentes de las sociedades latinoamericanas.

Sin embargo, ocurrieron algunos cambios, particularmente durante la segunda mitad del siglo XIX, que afectaron las posibilidades de la participación social. La transferencia en muchos países de las tierras de "manos muertas" de la Iglesia a la propiedad privada, la destruc-

2 Orlando Fals Borda, Las revoluciones inconclusas en América Latina (18091968), México, Siglo XXI Editores, 1968. 
ción de las comunidades indígenas por parte de las haciendas en expansión, la introducción de nuevos "cultivos comerciales en muchas zonas nuevas, el desarrollo del comercio y la actividad manufacturera bajo la ideología de laissez faire de la época, la emancipación de los esclavos en Brasil y su transformación en un proletariado rural marginalizado migratorio, la creciente ola de inmigración europea en los países del cono sur, las crecientes inversiones de capital extranjero privado en la minería, la agricultura y los servicios públicos, así como la incipiente industrialización; todos estos factores, junto con otros, contribuyeron a una transformación progresiva de las relaciones de clases $\mathrm{y}$ al surgimiento de nuevos grupos sociales en las zonas urbanas $\mathrm{y}$ rurales, que comenzaron a desafiar a la estructura vigente.

Estas tendencias continuaron durante el presente siglo, pero no lograron efectuar, cuando menos al principio, ningún cambio estructural fundamental. Sólo en México logró la revolución campesina de 1910 eliminar a la aristocracia latifundista (pero no inmediatamente), a través de una amplia reforma agraria, que permitió el firme establecimiento en el poder de nuevas clases sociales (principalmente la burguesía urbana contando con el apoyo de los llamados sectores medios).

La depresión de los años treinta y la segunda Guerra Mundial debilitaron el sistema tradicional. Si bien las economías latinoamericanas no perdieron su dependencia frente a las potencias metropolitanas mundiales (ahora principalmente los Estados Unidos) -en todo caso, esta dependencia se ha fortalecido durante los últimos treinta años-, sin embargo ha habido cierto grado de industrialización, sobre todo en Argentina, Brasil, Colombia y México. La emigración rural ha contribuido al enorme crecimiento urbano y junto con ello se ha transformado la estructura ocupacional, disminuyendo la importancia de las actividades primarias en beneficio de los sectores terciarios: el comercio, los servicios y la burocracia gubernamental están absorbiendo una parte creciente de la población considerada como económicamente activa.

Estos procesos de cambio, y otros más, han erosionado la base tradicional del poder del estado oligárquico, cuyo centro lo constituyen los grupos terratenientes y comerciales. El poder de éstos ha sido desafiado, pero no enteramente desplazado por la burguesía urbanoindustrial emergente. Sigue abierta la cuestión de si estos dos grupos están de hecho luchando entre sí por el predominio político, o si se acomodan mutuamente con el objeto de mantener el estado nacionaldependiente, y la respuesta depende desde luego de circunstancias históricas particulares. En todo caso, de acuerdo con ciertos autores, se ha desarroilado una crisis política en América Latina que tiene dos aspectos: por una parte, la crisis hegemónica de la oligarquía, y por la otra, la crisis hegemónica de la emergente burguesía urbana. La implicación de esta doble crisis es que ninguno de los dos grupos mencionados dispone, de hecho, de poder suficiente para establecer su propia hegemonía sobre la sociedad en su conjunto, y ni siquiera sobre las diversas facciones o sectores de la burguesía gobernante. Esto ha llevado a la burguesía urbano-industrial a buscar apoyo entre otros grupos sociales, tales como la clase media urbana y la clase obre- 
ra organizada. Estas alianzas han conducido ocasionalmente a gobiernos de tipo populista. ${ }^{3}$

La dominación oligárquica en América Latina se está desgastando históricamente, y la crisis hegemónica de la oligarquía simplemente anticipa su eventual desaparición de la escena política. En cambio, la crisis hegemónica de la burguesía urbana es más complicada, porque indica la incapacidad de esta clase para establecer su legitimidad en la sociedad en una etapa históricamente importante en América Latina, en que están surgiendo otros grupos que desafiarán cada vez más el orden burgués. Así, Quijano señala que "paralelamente a la crisis de las instituciones y mecanismos de legitimación del orden burgués, se observa también una modificación profunda en las relaciones entre la clase dominante y las instituciones fundamentales de represión como las fuerzas armadas, a partir de lo cual puede esperarse igualmente el ingreso de esta institución en un período de crisis. La modificación de las relaciones entre la clase dominante y las fuerzas armadas parece consistir, más visiblemente, en que mientras que antes su función principal era - desde el punto de vista de las relaciones de poder político- la represión de los movimientos populares y la representación de la clase en el poder del Estado cuando eso era necesario, pero bajo el control y la dirección inmediata de la clase dominante, los hechos recientes en algunos países parecerían indicar que la presencia en el manejo del Estado de las fuerzas armadas se realiza de manera relativamente independiente de la voluntad expresa de la clase dominante, y aun en contra de sus intereses políticos inmediatos, y de sus élites políticas más destacadas".4

El mismo autor concluye: "La crisis de la hegemonía política dentro de la clase dominante y la tendencia creciente de crisis de la legitimidad de la dominación de la clase en su conjunte, parecen pues haber ido creando las condiciones para que los sectores intermediarios de autoridad -ejército, Iglesia, burocracia estatal, principalmente- ganen un margen relativamente ampiio de autonomización relativa de sus relaciones con la clase burguesa y con el resto de la sociedad, mientras esta crisis de hegemonía perdure". ${ }^{5}$

La concentración del poder político y económico ocurre a varios niveles. A nivel ecológico, se manifiesta por el predominio de un pequeño número de centros urbanos sobre extensas áreas rurales atrasadas. El peso económico y político de las capitales y otras grandes ciudades en los países de América Latina ha sido señalado con frecuencia. ${ }^{6} \mathrm{La}$ importancia en sus respectivos países de aglomeraciones urbanas tales como Buenos Aires, Santiago, el triángulo São Paulo-

3 Torcuato Di Tella, "El populismo y la participación social", ponencia pre sentada en el Simposio sobre Participación Social en América Latina, IIEL, México, 14-16 de octubre de 1969 (mimeografiado).

4 Aníbal Quijano, "El marco estructural condicionante de los problemas de participación social en América Latina", ponencia presentada en el Simposio sobre Participación Social en América Latina, IIEL, México, 1416 de octubre de 1969 (mimeografiado), p. 35.

5 Ibid., p. 36.

6 Philip M. Hauser, La urbanización en América Latina, París, UNESCO, 1961; Glenn H. Beyer (Comp.), The Urban Explosion in Latin America, Ithaca, Nueva York, Cornell University Press, 1967; y J. E. Hardoy y C. Tobar, La urbanización en América Latina, Buenos Aires, Editorial del Instituto, 1969. 
Belo Horizonte-Río de Janeiro, Lima, Caracas o la ciudad de México, ha llevado a algunos autores a considerar a los países latinoamericanos como urbanos o urbanizados, más bien que como sociedades rurales tradicionales. Una buena parte de la población y una parte aún mayor de la riqueza, las actividades industriales, los servicios educativos y otros servicios públicos se concentra en estos núcleos urbanos.7

Al nivel sociocultural, el poder económico y político está con frecuencia en manos de minorías específicas que pueden ser identificadas en términos étnicos o raciales. Esto acontece desde luego principalmente en los países que tienen importantes poblaciones indígenas que han estado subordinadas tradicionalmente a los blancos o mestizos. Pero también ha ocurrido en el Brasil, en donde la incorporación de los antiguos esclavos negros a la estructura de clases capitalista ha tenido características particulares. 8

Al nivel sociopolítico, se han mencionado ya las formas "oligárquicas" tradicionales de control y autoridad. Éstas han tenido éxito, a través de su autolegitimación, en mantener la polarización de la estructura social y la rigidez de la pirámide social.

La polarización social y económica de los países latinoamericanos ha conducido a algunos observadores a hablar de un "dualismo" y de la existencia de "sociedades duales". En esencia, la tesis de la sociedad dual afirma que existen en los países latinoamericanos dos sociedades diferentes y hasta cierto punto independientes aunque necesariamente ligadas entre sí-: la primera sería una sociedad arcaica, tradicional, agraria, estancada y retrógrada; la segunda sería una sociedad moderna, urbana, industrializada, dinámica, progresista y en desarrollo. La "sociedad arcaica" está caracterizada por relaciones personales y familísticas, por instituciones tradicionales tales como el compadrazgo, ciertos tipos de trabajo colectivo, ciertas formas de dominación política personalista y relaciones de clientela. También aparecen en ella las estratificaciones rígidas basadas en los status sociales adscritos (en las que la posición del individuo en la estructura social está determinada desde el nacimiento y existen pocas oportunidades para que la modifique durante su vida); y las normas y valores exaltan -o cuando menos aceptan- el status quo y las formas tradicionales de vida social heredadas del pasado, y constituyen de esta manera un obstáculo al pensamiento económico "racional". En cambio, la "sociedad moderna" consistiría en ciertos tipos de relaciones sociales que los sociólogos llaman secundarias, determinadas por acciones interpersonales motivadas por finalidades racionales y utilitarias; de instituciones con funciones específicas; y de estratificaciones sociales relativamente flexibles en las que el status es adquirido a través del esfuerzo personal y puede expresarse mediante indices cuantitativos

7 La proporción de la población total concentrada en la ciudad más poblada del país es $46 \%$ en Uruguay, $30 \%$ en Argentina, alrededor de $25 \%$ en Chile, Panamá y Costa Rica, $18 \%$ en Cuba, Venezuela y México, $15 \%$ en Nicaragua y Perú, $12 \%$ en la República Dominicana y $10 \%$ en El Salvador, Guatemala y Bolivia. En algunos casos estas cifras son más altas porque la zona metropolitana en realidad cubre varias unidades administrativas que son contadas separadamente en los censos.

8 Véase Florestán Fernandes, A integração do negro à sociedade de classes, São Paulo, Editôra da Universidade de São Paulo, 1965. 
(tales como el nivel de ingresos o de educación) y la función social (como la ocupación). En la llamada "sociedad moderna" las normas y valores de la gente tienden a orientarse hacia el cambio, el progreso, la innovación y la racionalidad económica. ${ }^{9}$

Lo que aparece ser a primera vista un contraste entre dos sectores opuestos de una "sociedad dual" es de hecho el resultado de la interpenetración de fuerzas históricas que han permitido el crecimiento y la modernización de un segmento limitado de la sociedad y que no solamente han erigido obstáculos formidables al desarrollo del resto del país sino también han promovido, a veces, el continuado subdesarrollo de las zonas atrasadas y de sus poblaciones. ${ }^{10}$

Es posible calificar las relaciones entre los sectores duales de colonialismo interno, porque "el tipo de relaciones que se establecieron entre la metrópoli colonial y sus colonias se repitieron dentro de los propios países coloniales en las relaciones que se fueron desarrollando entre unos cuantos 'polos de crecimiento' y el resto del país... De hecho, las regiones atrasadas, subdesarrolladas de nuestros países siempre han desempeñado el papel de colonias internas con respecto a los centros urbanos en desarrollo y a las áreas agrícolas productivas".11

En una situación de colonialismo interno, la participación social tiende a estar limitada a los centros "metropolitanos" internos y a sus poblaciones. Sin embargo, el proceso de modernización que ocurre en estos centros metropolitanos en expansión no conduce necesariamente a la transformación del sector "colonizado", o de toda la población de estos centros, en poblaciones "participantes".

Las cambiantes relaciones de clases a las que se ha hecho referencia anteriormente, así como las transformaciones de la naturaleza del Estado, requieren de la incorporación creciente de las masas de la población a las estructuras sociales y económicas generales de la nación. En otras palabras, la sociedad nacional debe extender su dominio y su control sobre todos los sectores, subordinando intereses regionales, locales o particulares.

Esto, desde luego, no significa la eliminación de las desigualdades regionales o de clases, sino más bien la generalización de tipos más homogéneos de estructuras sociales y políticas, de sistemas administrativos y de relaciones económicas. Así, las formas precapitalistas de economía de poblaciones tribales o indígenas tienden a desaparecer; los tipos tradicionales de tenencia de la tierra comunal tienden a modificarse; las formas locales e independientes de poder personal y de relaciones de patronazgo/clientela tienden a incorporarse a las formas más racionales e institucionalizadas de control político ejercidas por el estado-nación central. Este proceso de incorporación reduce los aspectos "dualistas" de la sociedad y fortalece la situación de colonialismo interno descrita anteriormente. Es evidente que estos procesos de integración no significan que cada uno de los grupos así incorporados adquiera una capacidad igual para la participación orga-

9 Rodolfo Stavenhagen, "Siete tesis equivocadas sobre América Latina", El Dia, México, 25 de junio de 1965.

10 Véase F. H. Cardoso y E. Faletto, Dependencia y desarrollo en América Latina, México, Siglo XXI Editores, 1969; y A. G. Frank, Capitalism and Underdevelopment in Latin America, Nueva York, Monthly Review Press, 1967.

II Stavenhagen, loc. cit. 
nizada y consciente en la determinación de sus relaciones con el Estado y con los demás grupos en la estructura global del poder de la sociedad. Así tiene lugar simultáneamente un proceso de marginalización rural-urbana.

\section{El CONCEPTO DE MARGINALIDAD}

Tal como se utilizó originalmente, el concepto de "poblaciones marginales" se refería a los habitantes de los barrios urbanos marginales que ocupaban viviendas precarias en las márgenes de las principales ciudades latinoamericanas. Abundan las descripciones de las favelas de Río de Janeiro, las callampas de Santiago, las barriadas de Lima y fenómenos semejantes en otras partes. Pronto resultó evidente que el problema del alojamiento "marginal" no constituía solamente materia de preocupación para los urbanistas, sino que estaba vinculado a otras condiciones sociales, culturales y económicas. Así, se advirtió que las personas que vivían en los barrios "marginales" tenían niveles de vida sumamente bajos, participaban poco en la economía de consumo, acusaban altos índices de subempleo y desempleo, solían ser inmigrantes recientes de origen rural y no participaban -o participaban poco- en el sistema político. Pero éstas y otras características similares no eran exclusivas de los habitantes de los barrios marginales; estas características también eran propias de otros medios ambientes urbanos y de las áreas rurales.

Así, los "marginales" llegaron a ser los desposeídos de la sociedad latinoamericana, "aquellos que 'no pertenecen'... [que] están ubicados en la parte inferior de la escala social, o más bien fuera de ella. Puede decirse que no están social y económicamente integrados a una sociedad, a un sistema de clases, ya que no pertenecen al sistema económico. Están en el límite matemático, sin ser, pues no se encuentra en el campo, que los expulsa, ni en la ciudad, que no los acoge: no pertenecen al sector primario ni al secundario, no son nadie, no hacen más que estar, poblar un pedazo de tierra, que es tierra de nadie".12 Esta descripción elocuente, si bien no muy científica, no es precisamente una definición heurística de la marginalidad, pero sí apunta a la pobreza y miseria de grandes masas de la población. Los mismos autores estiman que sólo la población marginal urbana representa ya 30 millones de personas en América Latina.

Si el concepto de marginalidad ha de ser algo más que un mero término descriptivo que se aplica a la población de bajos ingresos de una zona determinada, entonces debe ser relacionado a las condiciones generales de la estructura social mencionadas anteriormente. En este sentido, la marginalidad o la marginalización llega a ser un proceso continuo vinculado al desarrollo económico y al crecimiento demográfico de una zona. De hecho, el proceso de desarrollo capitalista en América Latina ha creado una masa creciente de personas que no están integradas sistemáticamente a la estructura ocupacional. Algo

12 Roger Vekemans e Ismael Silva Fuenzalida, "El concepto de marginalidad", en DESAL (Centro para el Desarrollo Económico y Social en América Latina), Marginalidad en América Latina: un ensayo de diagnóstico, Barcelona, Editorial Herder, 1969, p. 44. 
semejante ocurrió durante el proceso de industrialización en Europa y particularmente en Inglaterra. ${ }^{13}$ Pero en Europa occidental el sistema económico fue capaz tarde o temprano de incorporar a las poblaciones marginales o cuando menos de reducir su importancia numérica dentro del proceso general de desarrollo. Lo mismo no está aconteciendo en América Latina, debido a las condiciones históricas particulares dentro de las cuales se desenvuelve en la región el proceso de desarrollo y de industrialización. En la medida en que aparecen poblaciones marginales que son cada vez más difíciles de incorporar al proceso "natural" de desarrollo capitalista, es posible hablar de una "sobrepoblación relativa" en América Latina. José Nun ha analizado este problema cuidadosamente. ${ }^{14}$ Durante el auge del capitalismo industrial en el siglo XIX, esta población excedente fue considerada por Marx como un "ejército industrial de reserva", es decir, jugaba un papel determinado en el funcionamiento del capitalismo competitivo de la época. ¿Es posible caracterizar en los mismos términos a los marginales latinoamericanos? ¿Desempeñan ellos el mismo papel de un ejército industrial de reserva? Sería tentador responder a estas preguntas afirmativamente, pero Nun lleva el análisis más lejos e introduce ciertas salvedades.

Con frecuencia se ha señalado que la industrialización en América Latina no sigue los mismos patrones que en los países de Europa occidental. Esto se debe básicamente al uso creciente de tecnologías más avanzadas que ahorran mano de obra y al papel económico desempeñado por las grandes corporaciones multinacionales. Así, una parte creciente de la población no puede ser incorporada al proceso de industrialización, a lo cual debe añadirse que América Latina tiene una de las tasas más elevadas del mundo de crecimiento natural de la población. El producto industrial en América Latina está creciendo mucho más rápidamente que la fuerza de trabajo industrial. Masas de trabajadores no calificados o semicalificados se ven así obligados a dedicarse a actividades de baja productividad en el sector terciario de la economía, a las llamadas ocupaciones "marginales", tales como vendedores ambulantes, sirvientes domésticos, limpiabotas y muchas otras actividades de subsistencia que realmente es difícil caracterizar como "empleo" en el sentido que se da a ese término en los países industrializados. Algunas de estas personas son realmente los clásicos desempleados que constituyen un "ejército industrial de reserva", esperando competir los unos contra los otros por obtener empleos escasos y ayudando así a mantener bajos los ingresos reales. Sin embargo, una parte creciente de esta población no sólo está desempleada, sino que es inempleable a los niveles tecnológicos actuales. A éstos, Nun los caracteriza como una "masa marginal" y ellos representan el verdadero problema de la marginalidad.

En contraste con el tipo clásico de un ejército industrial de reser-

13 Véase Eric Hobsbawm, "La marginalidad social en la historia de la industrialización europea", Revista Latinoamericana de Sociología, Buenos Aires, 1969, Núm. 2.

14 Cf. José Nun, "Superpoblación relativa, ejército industrial de reserva y masa marginal", en ibid.; y "Marginalidad y participación social, un planteo introductorio", documento presentado en el Simposio sobre la Participación Social en América Latina, México, 14-16 de octubre de 1969 (mimeografiado). 
va, la masa marginal en América Latina no es funcional con relación al sistema económico vigente y esto contribuye al mantenimiento del "dualismo" estructural de la sociedad o de la situación de colonialismo interno. Surge ahora la cuestión siguiente: si la masa marginal, por definición, es una población no participante, ¿existe la posibilidad de que participe socialmente sin una transformación cualitativa previa del sistema económico y social vigente? ¿o puede considerarse la participación social como una variable autónoma que puede intervenir, dadas ciertas circunstancias, y que a su vez tendrá ciertos efectos sobre el sistema económico y social? Si es así, ¿entonces cuáles son estas circunstancias y cuáles serán esos efectos?

Infelizmente, la literatura sobre la marginalidad en América Latina ha prestado más atención a la identificación del problema que a la participación social (real o potencial) de las poblaciones marginales. Existen por cierto algunos estudios de casos de asociaciones voluntarias, patronazgo y clientelas políticas, comportamiento electoral, etc., entre las poblaciones marginales urbanas, pero por lo general nuestro conocimiento de los mecanismos y formas de participación social tiende a centrarse en las organizaciones e instituciones establecidas tales como los sindicatos, las organizaciones patronales, los partidos políticos y otros grupos de intereses reconocidos.

También existe aquí un problema epistemológico. El concepto de marginalidad como se ha descrito arriba no constituye necesariamente una definición unívoca que permita clasificar o describir con facilidad ciertos individuos. La pregunta de quién es o no es una persona marginal en determinado momento no es una pregunta muy útil. Tal como lo empleamos aquí, el término de marginalidad es más bien un concepto estructural, como el de "clase social" (al cual, por cierto, está emparentado). Pero si las poblaciones marginales son, por definición, aquellas que no participan en el sistema político y económico vigente, entonces cualquier forma de participación social en la que intervienen transformaría automáticamente su condición de marginales. Esto no constituye, por supuesto, el objeto de nuestro análisis. Pero una tal posibilidad deberá ser considerada como hipótesis a ser verificada mediante la investigación empírica de campo (previa definición clara de los conceptos empleados), en vez de ser tratada como una conclusión previa.

En los párrafos que anteceden se ha prestado especial atención al problema de la marginalidad en las sociedades latinoamericanas porque un análisis tradicional de la estructura social, en términos de clases sociales bien definidas que se encuentran colocadas en relación directa las unas con las otras (burguesía y proletariado industrial, clase media urbana, terrateniente y campesino, trabajador de plantaciones, etc.) no explica adecuadamente este fenómeno. Existen, desde luego, clases sociales que pueden ser consideradas como más o menos marginalizadas con respecto a la estructura dominante. La masa marginal tal como la define Nun puede colocarse en un extremo de una escala de marginalidad creciente o decreciente. Los peones o colonos de los latifundios tradicionales en las áreas más atrasadas de América Latina son considerados por algunos autores como estando sólo un poco menos marginalizados con respecto a las estruc- 
turas dominantes que los marginales urbanos, y sin embargo puede decirse de ellos que están integrados mucho más funcionalmente al sistema. La elaboración de una tipología o siquiera de una escala en la cual la marginalidad sería considerada como una variable perteneciente a diferentes grupos sociales no constituirá un procedimiento muy constructivo en esta etapa. La existencia de la marginalidad (no tanto como característica de tal o cual grupo social, sino como propiedad inherente a la estructura social latinoamericana en la etapa actual de su desarrollo) es un marco de referencia necesario en el análisis de la participación social.

\section{LA PARTICIPACIÓN SOCIAL EN LA ESTRUCTURA AGRARIA}

Recordemos que para nuestros propósitos hemos definido la participación social como cualquier tipo de actividad organizada mediante la cual un determinado grupo social de bajo status expresa sus necesidades o demandas, defiende sus intereses comunes e intenta lograr ciertos objetivos econćmicos, sociales o políticos, o presionar o influir sobre las autoridades públicas de manera directa o indirecta. El resultado de dicha acción puede ser un incremento en el poder de negociación político y económico o un mejoramiento del status social del grupo involucrado. No trataremos de construir aquí un modelo formal de la participación social, aunque pudiéramos determinar las diferentes formas de participación en términos, por ejemplo, del grado de organización o institucionalización de la actividad realizada; la amplitud y extensión de esta actividad en cuanto a sus metas, tácticas y membrecía; la intensidad o "profundidad" de la participación, etc.15

Nuestra principal preocupación aquí es la de analizar la participación social en diferentes tipos de ambientes y en varios niveles, y no la de proporcionar un marco analítico lógico para su estudio. Esto será una etapa posterior, basada en más material empírico. El resto de este artículo estará dedicado a una síntesis de la participación social en la estructura agraria.

En la estructura agraria tradicional de América Latina existe poca oportunidad para que la mayoría de la población campesina pueda participar institucionalmente en cualquier tipo de organizaciones que pudieran ayudarle a superar su posición social y política. Las asociaciones voluntarias son casi inexistentes. Las diversas capas de la población agrícola - los jornaleros, los aparceros, los semisiervos en las haciendas, los precaristas, los dueños de minifundios en las comunidades indígenas o en las márgenes de los latifundios, los trabajadores migratorios estacionales, etc.- están todas ellas integradas en una estructura política, social y económica antigua y estable que generalmente representa para los campesinos sólo pobreza, explotación, dominación y represión. ${ }^{16}$

15 Para un análisis de las diferentes variables posibles de un movimiento social (en este caso, de movimientos campesinos), que pudiera ser aplicado también al estudio de la participación social, vẻase Henry A. Landsberger, "Función que han desempeñado en el desarrollo las rebeliones y los movimientos campesinos: método de análisis", Boletín del IIEL, Núm. 4, febrero de 1968, pp. 9-92.

16 Esta situación ha sido descrita de la manera siguiente en un informe de la OIT: "Aunque también se encuentra en otras partes del mundo, el sistema de 
Ciertamente los miembros de las comunidades indígenas participan de manera organizada en el mantenimiento de las estructuras tradicionales de su comunidad, y las diversas clases de campesinos también participan en actividades sociales, religiosas y algunas veces incluso políticas de naturaleza periódica o rutinaria, cuya principal función es la continuidad del equilibrio social a nivel local.

colonato indígena parece ser especialmente tenaz en la región andina de Sudamérica, en la que se han desarrollado dos sistemas principales: según el primero, el peón agrícola tiene el disfrute de una parcela de tierra en la hacienda para dedicarla al cultivo o al pastoreo o a ambas cosas a la vez, como parte de su salario. Según cl otro, el trabajador queda obligado a labrar la tierra del latifundio a cambio de la totalidad o de una parte del alquiler de la parcela que cultiva como colono o como aparcero. La característica central es que la tierra y los préstamos que se conceden al colono o al peón indígena asalariado constituyen medios de evitar que éstos abandonen la hacienda.

"Por lo común, se trata de un sistema según el cual el contrato de arrendamiento y el contrato de trabajo se combinan en un solo acuerdo cuyos detalles difieren de un país a otro y algunas veces de una región a otra en un mismo país, según el canon conductivo se abone en servicios agrícolas - con o sin un jornal suplementario-, en frutos o de una manera mixta. En algunas regiones de la altiplanicie andina, el sistema más frecuente es el que se aplica a base de la prestación de servicios con una pequeña retribución subsidiaria en dinero o en especie. En otras, el terrateniente facilita al indio semillas, abonos y las herramientas necesarias y le anticipa dinero, para cuya devolución se le exige un pago en especie a un tipo de conversión que determina el propietario. De este modo, se abre una 'cuenta en especie', lo que a menudo da lugar a una situación de dependencia debido a la acumulación de las deudas que obliga al trabajador indígena a permanecer indefinidamente al servicio del terrateniente. Aunque la legislación nacional lo prohibe, según diversos autores uno de los elementos característicos de este régimen semifeudal de tenencia de la tierra en varios países de América Latina y Asia es que los colonos o aparceros indígenas tienen la obligación de prestar servicios personales gratuitos a los terratenientes y a sus acreedores, e incluso a veces a las autoridades locales, civiles, militares y hasta al clero. En muchos casos, esta costumbre parece representar una deformación de ciertas instituciones sociales y tradicionales de las tribus, tales como la prestación de ayuda y servicio mutuo en las labores de la comunidad". (Véase OIT, Condiciones de vida y de trabajo de las poblaciones indigenas en los paises independientes, Informe VIII (1), Conferencia Internacional del Trabajo, Trigésima Novena Reunión, Ginebra, 1956, pp. 76-77.)

Otro informe de la OIT lo describe de esta manera:

"Los aspectos negativos de las relaciones contractuales entre el locatario y el dueño de la tierra constituyen serios obstáculos para el mejoramiento progresivo de las condiciones de vida y de trabajo de los agricultores objeto del presente estudio. En efecto mientras tales relaciones no sean objeto de una reglamentación ordenada y equitativa, el agricultor que labra la tierra ajena no podrá satisfacer sus necesidades mínimas de estabilidad en el empleo, de perfeccionamiento profesional y de mejoramiento de su nivel de vida. Tales consideraciones son válidas aun dentro del marco paternalista en que en el mejor de los casos se encuentran los locatarios que no se hallan amparados por arreglos formales.

"Dadas las limitadas posibilidades de acceso a la propiedad de la tierra, el agricultor sin tierra tiene solamente una alternativa: o permanece en tal situación, renunciando a cualquier aspiración que pueda tener de superación social y económica, o emigra, cuando esto es posible, hacia las zonas urbanas o industriales que le ofrecen mejores perspectivas de ganarse la vida. Esta migración, que puede ser permanente o por un corto plazo, presenta siempre un carácter desorganizado o fortuito. El trabajador carece de la necesaria capacitación y sigue sin poder adquirirla, desconoce las posibilidades de empleo y no tiene otra experiencia que la del trabajo agrícola. Suele dejar en la aldea a su familia, mantiene estrechos vínculos con ella y continúa albergando el sentimiento de que pertenece a la tierra. Si tiene la fortuna de encontrar empleo, su primer deseo, desde el momento en que ha podido reunir algún dinero, es regresar a la tierra pensando que con sus pequeños ahorros podrá lograr mejor éxito en la agricultura. (Sigue) 
Pero la literatura sobre América Latina proporciona muchos ejemplos que demuestran cómo la estructura del poder en el medio rural funciona para impedir que los grupos de status bajo se organicen para modificar significativamente su posición con respecto a las clases dominantes. ${ }^{17}$ Entre los factores que inhiben la participación social de los campesinos podemos señalar los sistemas tradicionales de tenencia de la tierra, el trabajo forzado obligatorio de buena parte de la población rural, la ausencia de garantías legales que rijan las relaciones de trabajo en el campo, la importancia creciente de una masa inestable de trabajadores migratorios estacionales, el recurso a la fuerza por parte de los terratenientes con el objeto de eludir la ley o de imponer su propia "ley" a los campesinos, el clima general de temor e inseguridad en que pasan la mayor parte de su vida los campesinos y que un observador ha llamado la "cultura de la represión".18

Sin embargo, sería un error suponer que esta situación ha producido una pasividad completa de los campesinos. Por el contrario, para no ir más allá de los comienzos del siglo xx, la revolución agraria mexicana fue alimentada por rebeliones campesinas. En la región andina, una larga historia de movimientos campesinos precedió a las preocupaciones recientes con la reforma agraria (comenzando con la reforma boliviana de 1953). En Brasil, el campesino formaba el núcleo de varios movimientos mesiánicos que comenzaron a tener significado nacional desde mediados del siglo XIX. En Colombia, la persistencia de la violencia rural, vinculada a los problemas políticos del país, condujo directamente a varios tipos de guerrillas campesinas. En años recientes, movimientos políticos organizados tales como las ligas camponesas del nordeste del Brasil, han expresado las profundas necesidades de la población rural que durante tanto tiempo se mantuvo en silencio. El mismo papel lo desempeñan las actividades or-

"Los niveles de ingresos de estos agricultores dependen de la posibilidad de utilizar racionalmente los recursos disponibles. En América Latina, el empleo corriente de prácticas agrícolas inadecuadas, la limitación de la superficie cultivable y la carencia de medidas de fomento agrícola (por ejemplo, créditos), que permitan la producción de excedentes capitalizables, son factores que, separadamente o de concierto, limitan de manera automática el rendimiento del trabajo y tienen como consecuencia inmediata el subempleo crónico, ya sea en su forma visible o encubierta. La llamada 'agricultura del machete' constituye un ejemplo clásico de tal situación. A pesar de la gran fertilidad de la tierra virgen que es objeto de esta práctica de cultivo, sólo se obtienen de ella rendimientos mediocres, y eso a costa de una inversión de mano de obra que no guarda proporción alguna con su capacidad de producción potencial con arreglo a sistemas adecuados de cultivo. Además de las razones de orden tecnológico del tipo anteriormente señalado, los bajos ingresos y el subempleo son motivados por la exigua superficie de las parcelas que cultivan los agricultores en algunas regiones donde este factor es consecuencia directa de la creciente densidad de la población que vive de la tierra." (OIT, Los agricultores sin tierra en América Latina, Estudios y documentos, Nueva Serie, Núm. 47, Ginebra, 1957, pp. 114115.)

17 Esto está bien documentado en un estudio reciente de Ernest Feder, $A$ Review of Land Tenure Changes and of Land Reform in the 1960's, Santiago de Chile, CEPAL, 1968, particularmente el capítulo II (mimeografiado); así como en Gerrit Huizer, Report on the Study on the Role of Peasant Organisations in the Pracess of Agrarian Reform in Latin America, Ginebra, OIT, documento C.24/ 1969 (mimeografiado).

18 Allan Holmberg, "Some Relationship between Psycho-biological Deprivation and Cultural Change in the Andes", documento presentado en Cornell Latin American Year Conference, marzo 21-25 de 1966 (mimeografiado). 
ganizadas de los sindicatos de trabajadores rurales de las plantaciones y haciendas de Chile, Venezuela y América Central, así como en otros países.

Todas estas manifestaciones pueden ser consideradas como tipos de participación social. Trataremos de identificar algunas de sus características principales en los párrafos que siguen.

Las actividades colectivas organizadas de las poblaciones rurales han presentado siempre problemas particulares para los estudiosos. Las características geográficas y ecológicas vinculadas a formas tradicionales de vida comunitaria, o el mundo "cerrado" de los sistemas feudales o semifeudales de tenencia de la tierra y de relaciones de trabajo, han contribuido a que el surgimiento de los movimientos campesinos fuera bastante diferente al de los movimientos de trabajadores urbanos o de otras clases sociales. Cabe recordar la famosa afirmación de Marx de que los campesinos franceses constituían una clase social en el sentido en que las papas en un costal constituyen un costal de papas. Sin embargo, el paysan francés tiene muy poco en común con la población rural latinoamericana, y la pregunta de cómo y bajo qué condiciones ésta se organiza tiene una importancia capital para el proceso de cambio social y desarrollo en América Latina.

La experiencia histórica reciente de América Latina ofrece algunas ideas centrales en cuanto a la "organizabilidad" de las poblaciones campesinas en esta región del mundo. Un amplio estudio comparativo por Gerrit Huizer señala algunos puntos comunes de los movimientos campesinos. ${ }^{19}$

Se piensa con frecuencia que los movimientos de protesta e incluso las revoluciones tienen su origen entre las clases sociales más oprimidas y desposeídas. Bien que la opresión y la miseria extremas juegan indudablemente su papel, no es en los escaños más bajos de la jerarquía social donde han comenzado los movimientos campesinos en América Latina. La historia de las organizaciones campesinas en Bolivia, Brasil, México, Perú y otros países demuestra que la población rural realiza actividades organizadas en defensa de sus intereses amenazados no tanto en las áreas más atrasadas cuanto en regiones que han entrado ya en un proceso de modernización. Es en estas áreas, sometidas a fuerzas nuevas (generalmente los cultivos comerciales para la exportación), donde las clases terratenientes aumentaron sus presiones sobre los campesinos subordinados, ya sea desalojándolos de la tierra a la que tenían acceso legal como en Bolivia, o negándose a considerar ciertas demandas limitadas de los aparceros y arrendatarios, como en el nordeste del Brasil, o usurpando las tierras comunales como en México, o intentando aumentar las obligaciones de trabajo forzado de los peones como en Perú. ${ }^{20}$ En cada uno de estos casos, la reacción del campesino ha sido la de unificarse en defensa de sus intereses comunes y promover medidas pacíficas y legales ten-

19 Gerrit Huizer, op. cit.

20 Landsberger (op. cit.) sugiere que el punto de partida de los movimientos campesinos no se encuentra tanto en un determinado objetivo de las condiciones del campesino, como en la posición económica de la étite tradicional. Esta hipótesis no ha sido aún puesta a prueba en suficientes casos en América Latina como para confirmarla o rechazarla. 
dientes a resolver sus problemas. Frente a la oposición rígida y a veces violenta de los grupos dirigentes a estas acciones, los movimientos campesinos radicalizaron rápidamente sus demandas así como sus tácticas. La experiencia demuestra que en esta etapa dichos movimientos, encontrándose incapacitados para continuar sus actividades por sí solos, buscan ayuda externa. Así se establecen vínculos con sindicatos urbanos o grupos políticos, y el sistema político nacional o regional se ve envuelto en la contienda. En México, como en Bolivia, una actividad campesina esencialmente localizada coincidió con movimientos políticos revolucionarios a nivel nacional y condujo al país hacia sendas reformas agrarias. En otras regiones, la inquietud campesina fue canalizada de manera más "institucional", para incorporarse al sistema general de clientelas políticas (como en Venezuela), o bien fue desviada o simplemente reprimida como hace algunos años en el Perú y en Brasil.

El papel del liderazgo es importante en las primeras etapas de la organización campesina. En la mayoría de los movimientos estudiados por Huizer en América Latina, los dirigentes originales provenían de entre los propios campesinos, pero puede decirse que no eran campesinos "típicos". En términos de personalidad, varios de ellos tenían cualidades carismáticas bien definidas que les permitían mantener y extender su influencia y autoridad personal más allá de la sola época de crisis. Además, todos ellos tenían alguna experiencia previa de tipo "modernizante", en el sentido de poseer más educación formal que sus compañeros, o de haber viajado a la ciudad, a la capital del país o incluso al extranjero.

En etapas posteriores, particularmente allí donde un movimiento local se vinculó más o menos formalmente con organizaciones más amplias de nivel regional o nacional, el liderazgo fue tomado a veces por elementos externos, como organizadores políticos, abogados o maestros que se identificaban con la lucha de los campesinos.

Desde luego, existen diferentes tipos de poblaciones campesinas en América Latina y el problema de la participación social surge de manera muy diferente en cada caso. Para los propósitos de análisis y simplificación, es posible distinguir tres tipos principales:

1) El campesino en el sentido restringido de la palabra, es decir, un agricultor que posee en propiedad la tierra que trabaja o que la controla directamente con cierta autonomía, y que produce principalmente para el consumo local, con ayuda de su familia, en vez de hacerlo para obtener un beneficio monetario. Estas personas también producen para el mercado, al cual están integrados, pero no debe confundírseles con el empresario agrícola de mentalidad capitalista de los países industrializados. Los bajos niveles tecnológicos, las prácticas tradicionales, el predominio del trabajo familiar o comunal, la existencia de pequeños excedentes para el mercado, la ausencia casi completa de la acumulación de capital - todos estos elementos caracterizan al campesino tradicional quien puede ser propietario de su tierra, miembro de una comunidad indígena, arrendatario, o precarista según las circunstancias locales. 
2) El colono o peón acasillado que trabaja en las grandes haciendas en las que se le concede el privilegio de cultivar para sí una pequeña parcela de subsistencia a cambio de obligaciones laborales generalmente pesadas para con el patrón. La relación entre el terrateniente y el peón ha sido descrita con frecuencia como "feudal", y forma parte integral del sistema de la hacienda que de hecho constituye el sistema social fundamental en muchas partes de América Latina.21

3) El trabajador asalariado de las plantaciones modernas dedicado a la producción de cultivos comerciales para los mercados nacionales e internacionales. Éste es el verdadero "proletariado rural" de los paises latinoamericanos, cuyas condiciones de empleo y vida se asemejan a las de los trabajadores urbanos.

La participación social del campesinado está asociada actualmente de manera más estrecha a la organización de los campesinos durante el proceso de la reforma agraria. De hecho, la reforma agraria ha llegado a ser el tema central alrededor del cual se cristaliza toda la problemática de la organización campesina. Los tres tipos de campesinos descritos brevemente en los apartados anteriores tienden a organizarse alrededor de problemas diferentes, relacionados con su situación particular con respecto a la propiedad de la tierra y el proceso productivo. Las principales características de sus respectivas organizaciones también varían de manera correspondiente.

El campesino independiente parece tener grandes dificultades para establecer organizaciones permanentes. Es común que este tipo de organizaciones se estructure alrededor de la figura de un líder carismático que se encarga él mismo de todos los asuntos importantes, que toma las principales decisiones y cuya autoridad indisputada es aceptada por todos los miembros. La norma clásica de las relaciones patrono/clientela se recrea aquí, y cuando el dirigente adopta posiciones radicales o militantes la organización lo sigue. Pero si el dirigente vacila o es captado por el sistema - como sucede con tanta frecuencia- entonces la organización comienza a desintegrarse y se transforma en un mero vehículo para una política de clientelas.

Santos de Moraes ha señalado ${ }^{22}$ que las condiciones sociales y económicas de los campesinos individuales determinan, en gran medi-

21 Un estudio reciente del sistema agrario en siete países de América Latina lo describe de la siguiente manera: "Estas instituciones de tenencia son producto de la estructura del poder. Escuetamente, la propiedad de la tierra o su control representan poder en su sentido clásico, es decir, la habilidad real o potencial de hacer que otros hagan lo que uno quiere. El poder sobre la mano de obra rural se refleja en las instituciones de tenencia que ligan a los trabajadores a la tierra concediéndoles escasos ingresos y pocos derechos. Los pequeños arrendatarios, medieros y trabajadores de las grandes explotaciones no tienen otra alternativa para obtener trabajo y vivienda que la que ofrecen los propietarios. Los contratos de trabajo y arrendamiento aseguran que los aumentos de productividad o ganancias extraordinarias siempre beneficien al propietario..." (Véase S. L. Barraclough y A. L. Domike, "La estructura agraria en siete países de América Latina", El Trimestre Económico, Núm. 130, abril-junio de 1966.)

22 Clodomir Santos de Moraes, "Algunas consideraciones en torno a las organizaciones campesinas en Latinoamérica", documento presentado en el Simposio del IIEL sobre la Participación Social en América Latina, México, 1416 de octubre de 1969 (mimeografiado). 
da, la manera en que son capaces de formar organizaciones o movimientos campesinos. El campesino es un verdadero "artesano": está involucrado en el proceso productivo de comienzo a fin; trabaja por su cuenta y para sí en un marco familiar o, en el mejor de los casos, en un ambiente comunitario. Salvo la común división del trabajo por edad y sexo, el productor campesino independiente sabe poco de tareas especializadas $u$ organización racional colectiva de la producción agrícola. Es propietario, empresario y trabajador al mismo tiempo. Aunque ocasionalmente pueda emplear mano de obra asalariada, supervisa él mismo todas las operaciones. No está ligado orgánicamente a otros trabajadores que desempeñan tareas especializadas diferentes, sino más bien a otros campesinos como él, dedicados a procesos similares. Así, dice Santos de Moraes: "La estructura del proceso productivo en que está involucrado el campesino determina muchas de sus actitudes sociales y rasgos de su comportamiento ideológico en el momento en que participa dentro del grupo social". ${ }^{23}$ Es incapaz de participar activamente en la compleja estructura de un movimiento moderno porque los requisitos de este tipo de organizaciones tienden a ser incompatibles con la visión del mundo individualista y familística del campesino aislado. Por lo tanto, resulta relativamente fácil en estas organizaciones que un dirigente dinámico y emprendedor logre centralizar la mayoría de las tareas importantes en sus propias manos, y generalmente el campesino miembro no tiene inconveniente en que esto suceda. Santos de Moraes ha estudiado varias organizaciones campesinas en el Brasil y en América Central y concluye que con frecuencia su decadencia o fracaso después de un surgimiento inicial se debe parcialmente al conflicto inherente entre una estructura organizativa "moderna" y el carácter y la ideología esencialmente "campesinos" de sus miembros. Éste parece haber sido el caso de las ligas camponesas en el nordeste del Brasil y también pasa frecuentemente con las cooperativas de propósitos múltiples y los grupos de acción al nivel de la comunidad, auspiciados por el gobierno como parte de proyectos de desarrollo rural.

Los movimientos sociales y políticos en los que participan comúnmente los peones de las haciendas se enfrentan a problemas organizativos semejantes. En estos casos, sin embargo, los objetivos básicos con frecuencia logran superar estas dificultades debido a su impacto sobre la estructura social total. De hecho, la mayoría de estos movimientos puede ser descrita en términos de la lucha por la tierra, lo que significa, en el marco de la estructura agraria de la mayor parte de América Latina, una lucha por la transformación radical del sistema social. Estos movimientos, siendo esencialmente subversivos del orden establecido, son resistidos tenaz y en ocasiones violentamente por la clase terrateniente en el poder. La experiencia de varios países ha demostrado que estos movimientos, iniciados por los peones o los agricultores sin tierras, tienen por objetivo la recuperación o restitución de las tierras con respecto a las que reclaman derechos ancestrales, o bien la obtención de títulos legales y derechos de propiedad sobre la tierra que ocupan y trabajan. No parece que dichos movi- 
mientos puedan tener éxito si no reciben apoyo de grupos poderosos $o$ revolucionarios a nivel nacional. $O$ bien desaparecen porque logran promover algún tipo de reforma agraria, como sucedió en Bolivia y México, y a nivel local en Perú (antes de la reforma reciente de 1969), en Chile y en Venezuela (y, desde luego, en el marco de una transformación total de la sociedad en Cuba), o bien son reprimidos o desmantelados por las autoridades. Esto ocurre con mucha mayor frecuencia y es lo que ha acontecido en menor o mayor grado en la mayoría de los países latinoamericanos.

Las características organizativas de los trabajadores de las plantaciones y otros asalariados en las grandes haciendas son muy diferentes. Santos de Moraes sugiere que la especialización y división del trabajo en las empresas agrícolas modernas tienden a favorecer la participación del trabajador de la hacienda en organizaciones complejas, bien estructuradas, como los sindicatos de trabajadores de plantaciones. "Si la empresa tiene una compleja estructura de producción, sus obreros también pueden crear y desarrollar un mecanismo social de compleja estructura orgánica, con sectores de producción, consumo, transporte, educación, vivienda, entretenimiento, crédito, etc." 24 E1 autor proporciona ejemplos de sindicatos y federaciones de trabajadores rurales de varios países, que son fuertes y eficientes y cuentan a veces con miles de miembros y que logran mantener un elevado nivel de actividad y servicios satisfactorios para sus miembros en varios campos.

Desde el punto de vista organizativo, los sindicatos de trabajadores rurales pueden ser comparados con los sindicatos urbano-industriales. Pero las implicaciones más amplias de la sindicalización rural conducen a establecer algunas diferencias importantes entre los dos tipos de organización. Almino Affonso lo ha señalado claramente: "El sindicado industrial no significa un desafio al orden social vigente. Las relaciones entre patrones y obreros no se alteran en esencia, por el hecho de que los trabajadores constituyan una organización representativa de sus intereses. Los elementos típicos de un contrato de trabajo siguen intocados: la prestación del servicio pactado, el vínculo de subordinación jerárquica y la contraprestación salarial. El patrón no es menos patrón por el hecho de dialogar con sus trabajadores, representados por un sindicato. En el campo, al revés, todo cambia. En el momento en que los campesinos se organizan en sindicatos hay como una transfiguración de las relaciones sociales: la 'dependencia', la 'lealtad', la 'sumisión', características del campesinado en la sociedad tradicional o transicional (adonde todavía esos valores sobreviven) se rompen $\mathrm{y}$ se establece un nuevo relacionamiento entre sujetos de derechos... Por el solo hecho de que los trabajadores se autorrepresenten, la verticalidad de las relaciones (antes aceptadas como algo inherente al orden natural) ya no puede subsistir. El patrón deja de ser el señor, pierde sus dimensiones míticas y se reduce a la proporción de un empleador".25 El hecho de que la sindicaliza.

25 Almino Affonso, "El sindicato campesino. agente de cambio", documento presentado al Simposio del IIEL sobre la Participación Social en América Latina, México, 1416 de octubre de 1969 (mimeografiado). 
ción rural, legalmente aceptada en la mayoría de los países latinoamericanos de una manera u otra, represente un desafío a las bases mismas en que ha descansado la estructura agraria durante cuatro siglos, explica la resistencia intransigente que le opone la estructura tradicional del poder. Con frecuencia se les niega a los campesinos los derechos constitucionales, muchas leyes no son más que letra muerta y toda clase de presiones son ejercidas sobre los trabajadores para impedir su organización. Esto explica el hecho que los sindicatos de trabajadores rurales, bien que hayan llegado a ser importantes en algunas regiones en que las circunstancias los han favorecido, sólo han podido agrupar a una proporción relativamente pequeña de la totalidad de la fuerza de trabajo agrícola en América Latina.

La situación descrita por Affonso y documentada por muchos otros estudios sobre la estructura agraria en América Latina no sólo se aplica a los movimientos cuyo objetivo explícito es la transformación radical de las relaciones de tenencia de la tierra, es decir, aquellos que luchan por una reforma agraria profunda. De hecho, los estudios de sindicatos rurales realizados por Affonso en Chile y en otros países durante varios años (precisamente durante los años sesenta en que la reforma agraria llegó a ser una cuestión nacional e internacional en América Latina) demuestran que en la mayoría de estos sindicatos las peticiones por la tierra desempeñan en realidad un papel poco importante en el proceso de negociación colectiva. Las presiones ejercidas por los trabajadores rurales a través de sus peticiones e incluso en sus huelgas tienen generalmente por objeto sólo medidas económicas: sueldos, empleos, seguridad en el empleo, beneficios sociales. Incluso las invasiones pacíficas de las haciendas por los trabajadores agrícolas (actos que son considerados con frecuencia como medidas radicales de los campesinos para presionar en favor de la reforma agraria) no han sido, en algunos casos, más que medidas tomadas para obtener algunos de los objetivos económicos mencionados anteriormente, y no intentos de obtener directamente la posesión de la tierra.

Bien que sea difícil generalizar sobre este problema para la América Latina en su totalidad, no hay duda que los movimientos campesinos dirigidos directamente a la reforma agraria se producen con mayor frecuencia en las zonas en que existe el peonaje o colonato, ${ }^{26}$ o en aquellas en que las poblaciones indígenas han sufrido despojos progresivos de sus tierras comunales por parte de las haciendas. Exigencias de tipo más económico serán presentadas por los sindicatos o agrupaciones de trabajadores agrícolas en aquellas áreas en que las relaciones entre trabajadores y empleadores son más "modernas", en donde prevalecen las remuneraciones monetarias aun cuando estén acompañadas de obligaciones y privilegios no-monetarios, y en donde la producción tiende a estar orientada hacia el mercado más que hacia el consumo local.

26 Para un excelente análisis de un caso de "neofeudalismo" que desembocó en una revuelta campesina, véase Eric J. Hobsbawm, "Problèmes agraires à la Convención (Pérou)", en Les problèmes agraires des Amériques Latines, París, Centre National de la Recherche Scientifique, 1967, y "A Case of Neo-Feudalism: La Convención, Peru", Journat of Latin American Studies, Vol. I, Parte I, Cambridge, Cambridge University Press, mayo de 1969. 
Los movimientos campesinos estructurados tales como los sindicatos o ligas mencionados en los párrafos anteriores no constituyen los únicos tipos de participación social, ni siquiera los más frecuentes, en que se integran las poblaciones rurales de América Latina como reacción contra el sistema social y económico en el que viven.

En algunas regiones, y particularmente en el Brasil, los movimientos de tipo mesiánico han podido movilizar en distintas épocas a miles de campesinos, a veces durante muchos años. La importancia sacial y política de los movimientos mesiánicos y milenaristas ha llamado la atención de los estudiosos sólo recientemente. Solían ser considerados exclusivamente desde el punto de vista religioso, pero los estudios de Hobsbawm, Lanternari, Pereira de Queiroz y otros han señalado los vínculos que tienen estos movimientos con los factores estructurales de las sociedades tradicionales y con los procesos dinámicos del cambio social.

Los movimientos mesiánicos son religiosos sólo por la forma, dice María Isaura Pereira de Queiroz ${ }^{27}$ con respecto al Brasil, pero sus objetivos son socioeconómicos y políticos. Todos siguen ciclos regulares y su estructura jerárquica interna es similar. La autora distingue entre los movimientos mesiánicos revolucionarios, que surgen de crisis estructurales y se enfrentan al sistema social en su totalidad, y los movimientos mesiánicos reformistas, que surgen de crisis de organización y cuyo propósito es principalmente la "reorganización" de las relaciones sociales dentro de una estructura dada, sin poner en duda la existencia fundamental de una sociedad tradicional.

Según Pereira de Queiroz, los movimientos mesiánicos rurales en el Brasil son de este último tipo y no constituyen una forma de participación social, tal como ésta ha sido definida anteriormente, porque no tratan de cambiar la estructura existente ni total ni parcialmente, y tampoco contribuyen realmente a aumentar el poder de negociación política y económica y el status social de los grupos involucrados. Los movimientos mesiánicos estudiados por Pereira de Queiroz no son provocados por desequilibrios internos en la estructura económica y social, sino más bien por la desorganización a nivel del comportamiento individual y de la familia y su desajuste con respecto a valores tradicionales. Las estructuras del poder y las jerarquías sociales y económicas vigentes no son atacadas por estos movimientos, los cuales tampoco desencadenan procesos sociales de cambio estructural. Por el contrario, contribuyen a reestablecer estructuras antiguas y refuerzan sus valores dominantes. El dirigente de estos movimientos -el mesías- es, en el mejor de los casos, un intermediario entre sus seguidores y la estructura política regional o nacional; con frecuencia se transforma en un patrono del clásico tipo de patronazgo y clientelas.

Pereira de Queiroz analiza también un caso de actividad mesiánica urbana en el Brasil contrastándolo con los movimientos mesiánicos rurales. El ejemplo estudiado es más "revolucionario" que los movimientos rurales, porque en este caso el mesías y sus seguidores niegan la legitimidad de la sociedad capitalista urbana. Sin embargo, en vez

27 María Isaura Pereira de Queiroz, "Movimientos mesiánicos brasileños: instrumentos u obstáculos a la participación", Boletín del IIEL, Núm. 7, 1970. 
de tratar de transformar la estructura existente - lo cual sería un verdadero caso de participación social tal como la hemos definido con anterioridad - el movimiento la rechazó totalmente al retirarse sus miembros físicamente para crear una comunidad utópica nueva al margen de la sociedad. De esta manera, concluye la autora, ni el mesianismo reformista rural de la sociedad tradicional, ni el mesianismo revolucionario de una sociedad urbana capitalista, son ejemplos de la participación social en el cambio en función del desarrollo. Los movimientos mesiánicos en el Brasil representan, más bien, la evolución de un tipo de participación a otro dentro de la propia sociedad tradicional. Los movimientos rurales conducen a una participación social más profunda de los grupos e individuos involucrados en la sociedad tradicional total del Brasil rural; en cambio, el movimiento urbano se retira tanto de la sociedad tradicional como de la moderna y termina con la marginalización consciente del grupo mesiánico en su totalidad.

Muchos observadores de las regiones rurales en Latinoamérica han señalado el hecho que la violencia es casi endémica en ellas. Ésta ha sido utilizada sistemáticamente durante siglos por los grupos dominantes para mantener su poder y control sobre el campesino. En cambio, no necesitamos buscar muy lejos para encontrar importantes expresiones de contraviolencia como una reacción de la población rural a la estructura agraria del poder. Los estados latentes de rebelión campesina han conducido ya sea a las revueltas de masas indígenas como la de Tupac Amaru en el Perú, o la Guerra de Castas en el siglo XIX en México; o ya sea, en el otro extremo de la escala, a los estados más o menos permanentes de falta de garantías legales en las zonas rurales, de los que la violencia en Colombia es tal vez el ejemplo más dramático pero de ninguna manera el único. Desde el punto de vista social y político, la violencia rural es algo más que simplemente un alto índice de criminalidad en el campo. Tampoco puede ser descartada simplemente como un estado de anomia, como dirían algunos sociólogos. El ejemplo de Colombia demuestra que no existe aparentemente una relación directa entre el sistema de tenencia de la tierra y la violencia rural. Aun cuando la violencia desde arriba en contra de los campesinos parece bien ser una constante en la vida rural latinoamericana, la contraviolencia desde abajo aparece más bien como una de tantas respuestas posibles de los campesinos, cuyas características específicas tenderán a variar de acuerdo con las circunstancias. El bandolerismo social (como el de los cangaceiros en el Brasil) puede ser uno de los tipos de reacción.

Mucho antes de la formulación sistemática de demandas agrarias a nivel nacional, luchas agrarias más o menos violentas han ocurrido entre los comuneros indígenas y las haciendas, entre los agricultores y los ganaderos, entre los terratenientes, los precaristas, los peones y los aparceros. La lucha por la tierra es una parte integral de la historia latinoamericana, pero sólo en años recientes se ha incorporado a marcos relativamente institucionales o a actividades francamente revolucionarias. Esta lucha ha sido apoyada, y tal vez incluso iniciada, con frecuencia, por grupos de intereses políticos específicos o por caudillos locales y otros tipos de dirigentes. Sería un error considerar esta lucha 
simplemente como la expresión desorganizada de tensiones o desajustes estructurales. A veces ha representado intentos incipientes de soluciones mucho más globales.

Es legítimo preguntarse si el trasfondo de violencia casi permanente en América Latina puede conducir a formas más específicas e instrumentales de acción, es decir, a la participación social, o si debe continuar siendo "disfuncional" con respecto a los objetivos generales más amplios del desarrollo social y económico. Si la violencia agraria es de hecho provocada y alimentada por el funcionamiento de la estructura del poder ( $\mathrm{y}$ todavía queda por demostrarse de manera concluyente que éste es, en efecto, el caso), entonces ejerce a su vez un efecto sobre esta misma estructura. Pero aún queda por demostrarse de qué manera este efecto retroalimentador refuerza, transforma o corroe la estructura.

En años recientes, debido a circunstancias políticas bien conocidas, la violencia revolucionaria ha aumentado en las zonas rurales. Las guerrillas campesinas, vinculadas a grupos políticos extrarrurales e influenciados por los grandes temas ideológicos de nuestro tiempo, han aparecido en más de media docena de países latinoamericanos. Todavía queda por hacerse un análisis sociológico de sus éxitos y fracasos. Pero una cosa es clara: no se pueden atribuir solamente a factores tecnológicos o militares, o a las actitudes o tácticas de partidos políticos determinados. En la medida en que la incorporación de un individuo a un movimiento guerrillero representa una opción consciente, razonada, ideológica, la expresión de un compromiso personal llevado a sus últimas consecuencias, puede ser considerada como una forma particularmente pertinente de participación social.

Sería ocioso especular acerca del futuro de los movimientos guerrilleros rurales en América Latina. Pero si bien en la mayoría de los países latinoamericanos no parece probable, cuando menos a corto plazo, que logren las transformaciones estructurales que buscan sus proponentes, también es probable que seguirán surgiendo (como han surgido una y otra vez a lo largo de la historia latinoamericana), mientras no ocurran dichas transformaciones. ${ }^{28}$

Las investigaciones presentes sobre la violencia rural en América Latina no nos permiten llegar a conclusiones muy generales con respecto a su relación con la participación social tal como se ha definido aquí. Un estudio reciente efectuado en Venezuela por Silva Michelena demuestra que la propensión a la violencia entre los campesinos de ese país (en donde, por cierto, la estructura agraria es mucho menos opresiva que en otros países) es dos veces mayor que entre cualquier otro grupo social. ${ }^{29} \mathrm{El}$ mismo estudio revela también, sin embargo, que los campesinos venezolanos, a pesar de un alto grado de sindicalización (más de $25 \%$ ), son menos críticos de la política nacional que otras clases sociales. Los campesinos parecen tener conciencia de sus problemas económicos y la falta de ciertos servicios comunales bási-

28 Fals Borda, op. cit., capítulo 4.

29 José Agustín Silva Michelena, "La violencia rural como forma de participación social", documento presentado en el Simposio del IIEL sobre la Participación Social en América Latina, México, 14-16 de octubre de 1969 (mimeografiado). 
cos, pero sólo algunos son capaces de vincular esta conciencia a las condiciones generales del país. Así, sus luchas son de ámbito limitado, pero han contribuido, según Silva Michelena, al clima de violencia permanente en el campo.

Como se ha señalado anteriormente, el panorama de la participación en las estructuras agrarias de América Latina es amplio y complejo. Se extiende desde la violencia endémica y casi anárquica en un extremo, hasta las guerrillas revolucionarias altamente estructuradas en el otro; desde los movimientos mesiánicos de inspiración religiosa hasta los sindicatos de trabajadores agrícolas militantes y bien organizados en las economías modernas de plantación. Entre las variables sociales que deberán ser tomadas en consideración para un análisis sistemático de estos fenómenos, debemos recordar no sólo los sistemas de tenencia de la tierra y los marcos generales de tipo legal y político, sino también los sistemas de patronazgo de tipo tradicional y moderno, las estructuras comunales y con frecuencia la diferenciación étnica o racial-cultural. Además, no debemos perder de vista los sistemas nacionales más amplios, determinados históricamente, en los que están involucradas las estructuras agrarias, tales como la situación de colonialismo interno y el proceso de marginalización social dentro del desarrollo capitalista dependiente de las naciones latinoamericanas.

Los procesos contemporáneos de cambio social no ocurren espontáneamente. Más y más, los gobiernos nacionales desempeñan un papel activo en la canalización de las transformaciones sociales y económicas hacia la dirección deseada. En las sociedades agrarias, programas específicos de planificación regional o de desarrollo de la comunidad han sido diseñados para acelerar la modernización del campo, para estimular el crecimiento de la agricultura, para lograr la integración nacional..$^{30} \mathrm{La}$ participación social en su sentido más amplio es de capital importancia si el desarrollo ha de significar algo para millones de campesinos. En otras palabras, la participación social significa que el desarrollo es no solamente para el pueblo sino también por el pueblo. Es muy difícil poner en práctica este antiguo ideal en cualquier lugar y, como hemos tratado de mostrar, se enfrenta a dificultades especiales en América Latina.

$30 \mathrm{El}$ análisis de las políticas gubernamentales en relación con el problema de la participación social queda fuera del marco de este artículo introductorio y deberá ser tratado en otra ocasión. 